\title{
Comparison of Body Image Dissatisfaction in Postpartum Mothers after Normal and Cesarean Delivery
}

\author{
Sreelatha Pasupuleti ${ }^{1}$, Mulinti Suresh Kumar ${ }^{2}$
}

\begin{abstract}
Background: Body image disturbances are not limited to young women but occur across all age-groups. Postpartum mothers particularly are more vulnerable to dissatisfaction in body image.

Settings and design: This is a cross-sectional observational hospital-based study set in a rural tertiary care center.

Materials and methods: Postpartum mothers were approached after their delivery and those who consented were enrolled in the study. Body image dissatisfaction was assessed using the Multidimensional Body-Self Relations Questionnaire-Appearance Scale (MBSRQ-AS) along with Marital Adjustment Test and Socio-cultural Attitudes toward Appearance Questionnaire-3 (SATAQ-3). Self-designed questionnaire to obtain the sociodemographic and clinical variables of the patients was also incorporated.

Results: The modified bradykinesia rating scale subscales of appearance evaluation and appearance orientation show less body dissatisfaction in cesarean section postpartum mothers. Body image dissatisfaction was not significantly associated with either the marital satisfaction or the sociocultural influences, including the media as measured by SATAQ-3.

Conclusion: The current study contributes to the existing literature of body image disturbances in postpartum mothers. It also highlights the comparison of body image dissatisfaction in cesarean section and normal delivery in the background of existent scant literature in this area of research.

Keywords: Body image, Body perception, Mode of delivery, Postpartum.

Indian Journal of Private Psychiatry (2020): 10.5005/jp-journals-10067-0056
\end{abstract}

\section{INTRODUCTION}

Pregnancy and postpartum is a period of developmental transition over a short time span with significant impact on physiological and psychosocial events. ' One such psychological implication during this significant life event is the concerns of the body image. ${ }^{2}$ Body image is considered to be the internal representation or the personal view of the individual of one's own external/physical appearance. ${ }^{3}$ These representations have cognitive, affective, conscious, and unconscious components in relation to their bodies during the biological development and their social relationships. ${ }^{4}$ One aspect of the concept of body image is body dissatisfaction. Body dissatisfaction is the negative evaluation of one's own body ${ }^{5}$ as a consequence of perceived variance between the actual body image and ideal body image. ${ }^{3}$

Societal expectations of ideal body image of thinness which is further fueled by the influence of social media affect women across all age-groups. ${ }^{6,7}$ Pregnancy and postpartum further makes the individual vulnerable as they deviate from the norms of ideal weight dictated by society, which increases the risk of body dissatisfaction. Weight of women gradually increases during pregnancy and postpartum; if new mothers have unusual expectations of regaining their pre-pregnancy body weight and figure, it will increase the risk of body image disturbances. ${ }^{8}$ Body dissatisfaction was greater in postpartum when compared to pre-pregnancy and late pregnancy. Body dissatisfaction seems to be more severe six months postpartum. ${ }^{9}$ Understanding body dissatisfaction during the postpartum period is essential as research indicates numerous negative outcomes to the mother and the baby. Body dissatisfaction has been associated with depression, ${ }^{10}$ eating disorders, ${ }^{11}$ marital and sexual dissatisfaction. ${ }^{12}$ Women not satisfied with their body image are less likely to breastfeed. ${ }^{13}$
1,2 Department of Psychiatry, PES Institute of Medical Sciences and Research, Kuppam, Andhra Pradesh, India

Corresponding Author: Sreelatha Pasupuleti, Department of Psychiatry, PES Institute of Medical Sciences and Research, Kuppam, Andhra Pradesh, India, Phone: +91 9663399840, e-mail: drsreelathakumar@gmail.com

How to cite this article: Pasupuleti S, Kumar MS. Comparison of Body Image Dissatisfaction in Postpartum Mothers after Normal and Cesarean Delivery. Ind J Priv Psychiatry 2020;14(1):11-15.

Source of support: Nil

Conflict of interest: None

The experience of childbirth involves a combination of individual, medical, and social factors that interact to influence the physical and psychological outcomes, which alters the women's well-being and daily functioning. Mode of delivery is one such factor that has been consistently identified as affecting these outcomes. ${ }^{14}$ Cesarean section delivery has been associated with body image disturbances and low self-esteem. ${ }^{15}$ Childbirth and the transition to parenthood comprise of novel experiences for parents and can modify their marital relationship. Parents need to adapt from a couple to a family unit and adjust to role changes for each partner individually and in relation to one another. Marital adjustment is the accommodation of the couple to each other at a given time. ${ }^{16}$ Women's adaptation to delivery and childbirth and transition into postpartum depended on previous marital adjustment. Women who underwent cesarean section expressed fear of negative reactions of husband regarding their surgical scars, which would affect their marital relationship..$^{17}$ Research done in pregnant women's body image disturbances observed that body image concerns can vary across pregnancy in relation to the drastic

(c) The Author(s). 2020 Open Access This article is distributed under the terms of the Creative Commons Attribution 4.0 International License (https://creativecommons. org/licenses/by-nc/4.0/), which permits unrestricted use, distribution, and non-commercial reproduction in any medium, provided you give appropriate credit to the original author(s) and the source, provide a link to the Creative Commons license, and indicate if changes were made. The Creative Commons Public Domain Dedication waiver (http://creativecommons.org/publicdomain/zero/1.0/) applies to the data made available in this article, unless otherwise stated. 
physical changes, ${ }^{18}$ with higher levels of body image concerns noted in early pregnancy than in late pregnancy. ${ }^{19}$ Moreover, pre-pregnancy body image disturbances can affect concerns during pregnancy. ${ }^{20}$ Though body image concerns in pregnancy and postpartum have been studied in the past, focus was more on its relation to eating disorders and depression. So far, the literature on the association of mode of delivery to body image dissatisfaction and its effect on marital satisfaction are sparse. Hence, the present study aimed to compare the body image dissatisfaction in postpartum women who underwent cesarean section with postpartum women with normal vaginal delivery and to assess the association of marital satisfaction and sociocultural attitudes with body image dissatisfaction in postpartum mothers in both groups.

\section{Materials and Methods}

This is a cross-sectional study conducted at a tertiary care teaching hospital in South India. Postpartum women were approached after delivery during their stay in the hospital or on their visits to outpatient for follow-up. The purpose of this study was explained, and written informed consent was obtained from the participants before enrolling them in the study. Ethical clearance was obtained from the Institutional Ethics Committee. Convenience sampling technique was used for data collection. Data were collected over a period of 6 months. For this study, the postpartum period is taken as the period immediately after the birth of the child up to 6 weeks. Postpartum mothers who were aged above 18 years and who underwent cesarean section and normal delivery willing to give informed consent were included. Postpartum mothers with prior history of psychiatric disorders, intellectual disability, and assisted vaginal delivery were excluded.

The data were entered into MS Excel 2007 version and further analyzed using SPSS 20 (IBM Corp., Armonk, NY). For descriptive analysis, the categorical variables were analyzed by using percentages. For inferential analysis, the numerical data were analyzed using " $t$ " test, and categorical data were analyzed using chi-square test. Logistic regression will be used to study the association between various factors studied and the outcome, and " $p$ " <0.05 will be considered as statistically significant.

\section{ToOLS Used}

\section{Multidimensional Body-Self Relations Questionnaire- Appearance Scale}

It is a 34-item self-report inventory for the assessment of selfattitudinal aspects of the body image construct. The Multidimensional Body-Self Relations Questionnaire-Appearance Scale (MBSRQ-AS) includes the following subscales: appearance evaluation, appearance orientation, overweight preoccupation, self-classified weight, and the body area satisfaction scale (BASS). MBSRQ is intended for use with adults and adolescents ( 15 years or older). It has been used extensively and successfully in body image research. The questionnaire uses a five-point Likert scale with responses ranging from definitely disagree to definitely agree, or very dissatisfied to very satisfied. Higher scores on each subscale indicate more satisfaction with their body image. Reliability coefficients for the female population ranged from 0.74 to 0.91 on all subscales.

\section{Marital Adjustment Test}

This scale developed by Locke and Wallace is a measure of marital quality and satisfaction and addresses conflict among couples. It is a 15-item self-report with a cutoff score of 100 in which high scores indicate better marital satisfaction and more agreement between spouses. The measure is administered to each partner separately and is available in both paper-and-pencil and electronic formats. The scale has good reliability of 0.84 .

\section{Sociocultural Attitudes toward Appearance Questionnaire-3 $3^{21}$}

Body image literature suggests that the sociocultural environment contributes to the development and maintenance of body dissatisfaction. Among the various sources of sociocultural influences, the media appear to be the most powerful communicator of these standards. Thompson et al. developed a multidimensional questionnaire to assess the sociocultural influence of the media on appearance. ${ }^{21}$ SATAQ-3 is a 30 -item scale composed of Likert items in five points (1-completely disagree to 5-completely agree), including four subscales: information, pressures, internalizationgeneral, and internalization-athlete. Higher scores on the SATAQ-3 indicate that there are higher levels of involvement in SATAQ-3. High score reliability (Cronbach's alpha of 0.97 ) and structure similarity of the four subscales in diverse ethnic groups were observed. ${ }^{22}$

\section{Results}

Postpartum mothers who underwent cesarean section and normal delivery in a tertiary care teaching hospital in a rural background participated in this study. A total of 80 postpartum mothers consented and were included. Out of which, 34 (42.5\%) had cesarean section and 46 (57.5\%) had normal delivery. Majority of them 71 (88.75\%) had planned pregnancy, and 77 (96.25\%) breastfed their babies. Postpartum mothers with age-group of 18 to 23 were $32(40 \%)$ and 24 to 28 were 31 (38.7\%). Most of the participants had education of less than 10th standard ( $N=43,53.75 \%)$, marital duration of less than 6 years $(N=66,82.5 \%)$, with being a homemaker ( $N=49,61.25 \%)$, with a monthly income of less than INR 25,000 ( $N=75,93.75 \%$ ) (Table 1). Considering the postpartum days, 46 (57.5\%) were more than 20 days of the postpartum period. Postpartum mothers who were primipara were 43 (53.75\%). Majority of the participants had a normal BMI $(N=51,63.75 \%)$ and were satisfied with their marital life ( $N=78,97.5 \%)$ (Table 2).

Higher scores on the modified bradykinesia rating scale (MBRS) subscales of appearance evaluation and appearance orientation in cesarean section postpartum mothers indicative of less body dissatisfaction were observed, which were statistically significant (Table 3). When marital satisfaction was compared to the five subscales of MBRS (appearance evaluation, appearance orientation, overweight preoccupation, self-classified weight, and the BASS, no statistically significant differences were observed. Higher scores on appearance orientation subscale were found in postpartum mothers with less than 6 years of marriage, monthly income of less than INR 25,000, those staying in a joint family, which were statistically significant. High scores on body area satisfaction subscale were observed in those residing in a joint family, which was statistically significant. Low scores on overweight preoccupation subscale were found in postpartum mothers with planned pregnancy, which were statistically significant suggestive of body dissatisfaction (Table 4).

The body image dissatisfaction as measured by MBRS scale was not significantly associated with either the marital satisfaction or the sociocultural influences, including the media as measured by SATAQ-3. 
Body Image Dissatisfaction in Postpartum Mothers

Table 1: Sociodemographic profile of postpartum mothers

\begin{tabular}{|c|c|c|c|}
\hline \multicolumn{2}{|c|}{ Sociodemographic variables } & \multirow{2}{*}{$\begin{array}{l}\text { Frequency }(N) \\
32\end{array}$} & \multirow{2}{*}{$\frac{\text { Percentage }}{40.00}$} \\
\hline Age in years & $18-23$ & & \\
\hline & $24-28$ & 31 & 38.72 \\
\hline & $>28$ & 17 & 21.25 \\
\hline & Total & 80 & 100.00 \\
\hline \multirow[t]{4}{*}{ Education } & $<10$ th & 43 & 53.75 \\
\hline & $>10$ th & 31 & 38.75 \\
\hline & Illiterate & 6 & 7.50 \\
\hline & Total & 80 & 100.00 \\
\hline \multirow{3}{*}{$\begin{array}{l}\text { Marital duration } \\
\text { (in years) }\end{array}$} & $<6$ & 66 & 82.50 \\
\hline & $>6$ & 14 & 17.50 \\
\hline & Total & 80 & 100.00 \\
\hline \multirow[t]{3}{*}{ Occupation } & Employed & 31 & 38.75 \\
\hline & Housewife & 49 & 61.25 \\
\hline & Total & 80 & 100.00 \\
\hline \multirow{3}{*}{$\begin{array}{l}\text { Monthly income } \\
\text { (in rupees) }\end{array}$} & $<25,000$ & 75 & 93.75 \\
\hline & $>25,000$ & 5 & 6.25 \\
\hline & Total & 80 & 100.00 \\
\hline \multirow[t]{3}{*}{ Type of family } & Joint & 47 & 58.75 \\
\hline & Nuclear & 33 & 41.25 \\
\hline & Total & 80 & 100.00 \\
\hline \multirow{3}{*}{$\begin{array}{l}\text { Postpartum days } \\
\text { (in days) }\end{array}$} & $<20$ & 34 & 42.50 \\
\hline & $>20$ & 46 & 57.50 \\
\hline & Total & 80 & 100.00 \\
\hline \multirow[t]{3}{*}{ Parity } & Multiparas & 37 & 46.25 \\
\hline & Primipara & 43 & 53.75 \\
\hline & Total & 80 & 100.00 \\
\hline
\end{tabular}

\section{Discussion}

The current study set to observe body image dissatisfaction differences in postpartum mothers with normal and cesarean delivery and to find associations of marital satisfaction and sociocultural attitudes on body dissatisfaction in postpartum. Significant finding of this present study is that postpartum mothers who underwent cesarean delivery had less body dissatisfaction on two subscales (appearance evaluation and appearance orientation) as compared with mothers with normal delivery.

Mode of birth has an undue influence on the physical and psychological outcomes, especially during the initial few months of birth. It is interesting to note that nearly half of the study sample had undergone cesarean delivery. Studies depict a growing preference for cesarean delivery in Asia and other developing countries. ${ }^{23,24}$ Women who had planned or unplanned surgical intervention for childbirth experienced more body dissatisfaction associated with lower self-esteem compared to those with normal vaginal delivery. ${ }^{25,26}$ This is in contrast with this study where cesarean section mothers had higher body image satisfaction when compared to those mothers with vaginal delivery. One
Table 2: Clinical variables of postpartum mothers

\begin{tabular}{|c|c|c|c|}
\hline \multicolumn{2}{|c|}{ Sociodemographic variables } & \multirow{2}{*}{$\begin{array}{l}\text { Frequency }(\mathrm{N}) \\
42\end{array}$} & \multirow{2}{*}{$\frac{\text { Percentage }}{52.50}$} \\
\hline Gender of the baby & Female & & \\
\hline & Male & 38 & 47.50 \\
\hline & Total & 80 & 100.00 \\
\hline \multirow{3}{*}{$\begin{array}{l}\text { Body mass index } \\
\left(\mathrm{kg} / \mathrm{m}^{2}\right)\end{array}$} & $<18.5$ & 12 & 15.00 \\
\hline & $>25.0$ & 17 & 21.25 \\
\hline & Total & 80 & 100.00 \\
\hline \multirow[t]{3}{*}{ Breastfeeding } & No & 3 & 3.75 \\
\hline & Yes & 77 & 96.25 \\
\hline & Total & 80 & 100.00 \\
\hline \multirow[t]{3}{*}{ Type of delivery } & Cesarean & 46 & 57.50 \\
\hline & Normal & 34 & 42.50 \\
\hline & Total & 80 & 100.00 \\
\hline \multirow[t]{3}{*}{ Planned pregnancy } & No & 9 & 11.25 \\
\hline & Yes & 71 & 88.75 \\
\hline & Total & 80 & 100.00 \\
\hline \multirow[t]{3}{*}{ Marital satisfaction } & No & 2 & 2.50 \\
\hline & Yes & 78 & 97.50 \\
\hline & Total & 80 & 100.00 \\
\hline
\end{tabular}

possible explanation could be the increasing rates of cesarean sections in India, which reduces the perception of surgical delivery as abnormal ${ }^{27}$ and hence dampens the effect of psychosocial consequences, including body image disturbances.

The low levels of body dissatisfaction across the postpartum mothers in this study irrespective of mode of delivery could be because a study period of 6 weeks was considered. In another study, body image disturbances increased from 2-week postpartum to 8 -week postpartum. ${ }^{28}$ Another study states that body image dissatisfaction is most profound at six-month postpartum. ${ }^{9}$ The new demands of motherhood might have taken precedence over concerns of body image immediately after birth. Future research with prospective design with longer postpartum period of time frame can explore long-term changes in postpartum body dissatisfaction.

This study also tried to explore the effect on mode of delivery on marital adjustment and found no significant change. This is similar to study done by Culp and Osofsky which observed that cesarean delivery did not impact marital satisfaction of the couples. This study concluded that good marital satisfaction prenatally could have helped the couples support each other and cope with cesarean delivery. ${ }^{29}$

Previous studies observed that women who were more dissatisfied with their body image expressed greater concern on the impact of breastfeeding on their bodies. ${ }^{30,31}$ The current study observed that body dissatisfaction was not significantly associated with concerns of breastfeeding in mothers. Postpartum mothers feel the societal pressure to reclaim their pre-pregnancy bodies after delivery and consider this as a dreadful prospect..$^{32}$ The present study found that sociocultural attitudes had no impact on body image. Perceived social support and marital satisfaction could be associated with increased satisfaction with body image. ${ }^{33}$ 
Body Image Dissatisfaction in Postpartum Mothers

Table 3: Association between type of delivery and the modified bradykinesia rating scale (MBRS) subscales

\begin{tabular}{|c|c|c|c|c|c|}
\hline Type of delivery & MBRS subscales & & Total & Chi-square & $p$ value \\
\hline & \multicolumn{4}{|c|}{ MBRS-appearance evaluation $(<2.82 ;>2.82)$} & \\
\hline Cesarean & $13(37.14 \%)$ & $33(73.33 \%)$ & $46(57.50 \%)$ & 10.551 & $0.001^{*}$ \\
\hline Normal & $22(62.86 \%)$ & $12(26.67 \%)$ & $34(42.50 \%)$ & & \\
\hline \multirow[t]{2}{*}{ Total } & $35(100.00 \%)$ & 45 (100.00\%) & $80(100.00 \%)$ & & \\
\hline & \multicolumn{3}{|c|}{ MBRS - appearance orientation $(<3.15 ;>3.15)$} & & \\
\hline Cesarean & $20(46.51 \%)$ & $26(70.27 \%)$ & $46(57.50 \%)$ & 4.593 & $0.032^{*}$ \\
\hline Normal & $23(53.49 \%)$ & $11(29.73 \%)$ & $34(42.50 \%)$ & & \\
\hline Total & $43(100.00 \%)$ & $37(100.00 \%)$ & $80(100.00 \%)$ & & \\
\hline
\end{tabular}

Table 4: Association between sociodemographic variables and the modified bradykinesia rating scale (MBRS) subscales

\begin{tabular}{|c|c|c|c|c|c|c|}
\hline \multicolumn{2}{|l|}{ Sociodemographic variable } & \multicolumn{2}{|l|}{ MBRS subscales } & \multirow[t]{2}{*}{ Total } & \multirow[t]{2}{*}{ Chi-square } & \multirow[t]{2}{*}{$p$ value } \\
\hline & & MBRS-appear & ntation $(<3.15$ & & & \\
\hline \multirow[t]{4}{*}{ Marriage duration (in years) } & $<6$ & $32(74.42 \%)$ & $34(31.89 \%)$ & $66(82.50 \%)$ & 4.205 & $0.040^{*}$ \\
\hline & $>6$ & $11(25.58 \%)$ & $3(8.11 \%)$ & $14(17.50 \%)$ & & \\
\hline & Total & $43(100.00 \%)$ & $37(100.00 \%)$ & $80(100.00 \%)$ & & \\
\hline & & MBRS-appear & ntation $(<3.15$ & & & \\
\hline \multirow[t]{4}{*}{ Type of family } & Joint family & $21(48.84 \%)$ & $26(70.27 \%)$ & 47 (58.75\%) & 3.769 & $0.052^{*}$ \\
\hline & Nuclear family & $22(51.16 \%)$ & $11(29.73 \%)$ & $33(41.25 \%)$ & & \\
\hline & Total & $43(100.00 \%)$ & $37(100.00 \%)$ & $80(100.00 \%)$ & & \\
\hline & & MBRS-appear & ntation $(<3.15$ & & & \\
\hline \multirow[t]{4}{*}{ Monthly income (in rupees) } & $<25,000$ & $38(88.37 \%)$ & $37(100.00 \%)$ & 75 (93.75\%) & 4.589 & $0.032^{*}$ \\
\hline & $>25,000$ & $5(11.63 \%)$ & $0(0.00 \%)$ & $5(6.25 \%)$ & & \\
\hline & Total & $43(100.00 \%)$ & $37(100.00 \%)$ & $80(100.00 \%)$ & & \\
\hline & & MBRS—body a & action $(<3.16 ;>$ & & & \\
\hline \multirow[t]{4}{*}{ Type of family } & Joint family & $16(41.03 \%)$ & 31 (75.61\%) & 47 (58.75\%) & 9.864 & $0.002^{*}$ \\
\hline & Nuclear family & $23(58.97 \%)$ & $10(24.39 \%)$ & $33(41.25 \%)$ & & \\
\hline & Total & $39(100.00 \%)$ & $41(100.00 \%)$ & 80 (100.00\%) & & \\
\hline & & MBRS-body a & action $(<3.24 ;>$ & & & \\
\hline \multirow[t]{3}{*}{ Planned pregnancy } & No & $1(2.70 \%)$ & $8(18.60 \%)$ & $9(11.25 \%)$ & 5.036 & $0.025^{*}$ \\
\hline & Yes & $36(97.30 \%)$ & $35(81.40 \%)$ & 71 (88.75\%) & & \\
\hline & Total & 37 (100.00\%) & $43(100.00 \%)$ & $80(100.00 \% 0$ & & \\
\hline
\end{tabular}

Majority of the sample (88.75\%) had planned pregnancy; this did significantly influence the body image disturbances (body area satisfaction subscale of MBRS). In contrast, a study done in Iran showed better body satisfaction in those with planned pregnancy. ${ }^{34}$ Normal $\mathrm{BMI}$ was noted in majority of the postpartum mothers, and it did not significantly influence the body dissatisfaction. A study assessing attitude to body image in postpartum African American women found a slightly positive attitude to body image with little focus given on body weight by African American women. An understanding of the cultural impact on body image with friends and family contributing to attitude to body image was considered in this study. ${ }^{35}$

Limitations of our study were that the sample was collected at a single hospital with specific demographic characteristics. All of the mothers were married to most of them with low education and low socioeconomic status from a rural background. Hence, the results cannot be representative of the general population.

\section{Conclusion}

The psychosocial impact of a cesarean section particularly body image disturbances is rarely considered in risk-benefit analysis of decision making of cesarean delivery. Moreover, even after cesarean section, the current trend is to discharge the mother at the earliest if there are no postnatal complications. This leads to less focus on preparing the mother, especially first-time mothers. Apart from the changes in the family role functions and adapting to the demands of the baby, emphasis should also be on the body image concerns and expectations to regain the pre-pregnancy body weight. Healthcare providers should consider body image dissatisfaction 
in postpartum mothers and the contributing psychosocial variables in tailoring interventions.

Future directions

- As the current study was cross sectional in design, recommendations for future work could focus on prepregnancy, pregnancy, and postpartum body image disturbances in the same sample of women prospectively.

- Our study also did not explore mood dysfunctions like depression and eating disorders and their impact on body dissatisfaction.

- The impact of planned and unplanned cesarean section on body image was not evaluated as each of these factors can have different effects on the body image perception postpartum. Further research can focus on these aspects.

\section{References}

1. Rocco $P$, Orbitello $B$, Perini $L$, et al. Effects of pregnancy on eating attitudes and disorders: a prospective study. J Psychosom Res 2005;59(3):175-179. DOI: 10.1016/j.jpsychores.2005.03.002.

2. Walker L, Timmerman G, Kim M, et al. Relationships between body image and depressive symptoms during postpartum in ethnically diverse, low income women. Women Health 2005;36(3):101-121. DOI: 10.1300/J013v36n03_07.

3. Heider N, Spruyt A, De Houwer J. Body dissatisfaction revisited: on the importance of implicit beliefs about actual and ideal body image. Psychol Belg 2018;58(4):158-173. DOI: 10.5334/pb.362.

4. Thompson JK, Heinberg LJ, Altabe M, et al. Exacting beauty: theory, assessment, and treatment of body image disturbance; 1999. Washington, DC: American Psychological Association.

5. Presnell, K, Bearman SK, Stice E. Risk factors for body dissatisfaction in adolescent boys and girls: a prospective study. Int J Eat Disord 2004;36(4):389-401. DOI: 10.1002/eat.20045.

6. Stice E. Risk and maintenance factors for eating pathology: a metaanalytic review. Psychol Bull 2002;128(5):825-848. DOI: 10.1037/00332909.128.5.825.

7. de Vries DA, Vossen HGM, van der Kolk-van der Boom P. Social media and body dissatisfaction: investigating the attenuating role of positive parent-adolescent relationships. J Youth Adolesc 2019:48(3):527-536. DOI: 10.1007/s10964-018-0956-9.

8. Carter AS, Wood Baker C, Brownell KD. Body mass index, eating attitudes, and symptoms of depression and anxiety in pregnancy and the postpartum period. Psychosom Med 2000;62(2):264-270. DOI: 10.1097/00006842-200003000-00019.

9. Rallis $\mathrm{S}$, Skouteris $\mathrm{H}$, Wertheim EH, et al. Predictors of body image during the first year postpartum: a prospective study. Women Health 2007;45(1):87-104. DOI: 10.1300/J013v45n01_06.

10. Silveira ML, Ertel KA, Dole N, et al. The role of body image in prenatal and postpartum depression: a critical review of the literature. Arch Womens Ment Health 2015;18(3):409-421. DOI: 10.1007/s00737-015-0525-0.

11. Micali N, De Stavola B, Ploubidis G, et al. The effects of maternal eating disorders on offspring childhood and early adolescent psychiatric disorders. Int J Eat Disord 2014;47(4):385-393. DOI: 10.1002/eat.22216.

12. Mickelson KD, Joseph JA. Postpartum body satisfaction and intimacy in first-time parents. Sex Roles 2012;67:300-310. DOI: 10.1007/s11199012-0192-9.

13. Walker LO, Freeland-Graves JH, Milani T, et al. Weight and behavioral and psychosocial factors among ethnically diverse, low-income women after childbirth: I. Methods and context. Women Health 2004;40(2):1-17. DOI: 10.1300/J013v40n02_01.

14. Rowlands IJ, Redshaw M. Mode of birth and women's psychological and physical wellbeing in the postnatal period. BMC Pregnancy Childbirth 2012;12:138. DOI: 10.1186/1471-2393-12-138.
15. Lobel M, DeLuca RS. Psychosocial sequelae of cesarean delivery: review and analysis of their causes and implications. Soc Sci Med 2007;64(11):2272-2284. DOI: 10.1016/j.socscimed.2007.02.028.

16. Affonso DD, Stichler JF. Ceaserean birth:Women's reaction. Am J Nurs 1980;80(3):468-470.

17. Locke HJ, Wallace KM. Short marital adjustment and prediction tests: their reliability and validity. J Marriage Fam Living, 1959;21(3):251-255. DOI: $10.2307 / 348022$.

18. Skouteris $\mathrm{H}, \mathrm{Carr} \mathrm{R}$, Wertheim $\mathrm{EH}$, et al. A prospective study of factors that lead to body dissatisfaction during pregnancy. Body Image 2005;2(4):347-361. DOI: 10.1016/j.bodyim.2005.09.002.

19. Loth KA, Bauer KW, Wall M, et al. Body satisfaction during pregnancy. Body Image 2011;8(3):297-300. DOI: 10.1016/j.bodyim.2011.03.002.

20. Hodgkinson EL, Smith DM, Wittkowski A. Women's experiences of their pregnancy and postpartum body image: a systematic review and meta-synthesis. BMC Pregnancy Childbirth 2014;14:330. DOI: 10.1186/1471-2393-14-330.

21. Thompson JK, van den Berg $P$, Roehrig $M$, et al. The socio cultural attitudes towards appearance scale-3 (SATAQ-3): development and validation. Int J Eat Disord 2004;35(3):293-304. DOI: 10.1002/eat.10257.

22. Cortney W, Gleaves D, Akoury LM. Score reliability and factor similarity of the socio cultural attitudes towards appearance questionnaire-3 (SATAQ-3) among four ethnic groups. J Eat Disord 2013;1:14. DOI: 10.1186/2050-2974-1-14.

23. Matthews TG, Crowley $P$, Chang A, et al. Rising cesarean section rates: a cause for concern? BJOG 2003;110(4):346-349. DOI: 10.1046/j.14710528.2003.02010.x.

24. Kamdo I, Bedi N, Dhillon BS, et al. A critical appraisal of cesarean section rates at a teaching hospital in India. Int J Gynecol Obstet 2002;79(2):151-158. DOI: 10.1016/s0020-7292(02)00226-6.

25. Birdsong LS. Loss and grieving in cesarean mothers. In: KC Fitzgerald, ed. The cesarean experience; 1981. New York, NY: Appleton-Century Croft.

26. Mercer R., Stainton M. Perceptions of the birth experience: a cross cultural comparison. Health Care Women Int 1984;5(1-3):29-47. DOI: 10.1080/07399338409515637.

27. Chen $\mathrm{CH}$, Wang SY. Psychosocial outcomes of vaginal and cesarean births in Taiwanese Primiparas. Res Nurs Health 2002;25(6):452-458. DOI: 10.1002/nur.10056.

28. Miovech SM, Helen K, Borucki L, et al. Major concerns of women after cesarean delivery. J Obstet Gynecol Neonatal Nurs 1994 Jan;23(1):53-59. DOI: 10.1111/j.1552-6909.1994.tb01850.x.

29. Culp RE, Osofsky HJ. Effects of cesarean delivery on parental depression, marital adjustment, and mother-infant interaction. Birth 1989;16(2):53-57. DOI: 10.1111/j.1523-536x.1989.tb00860.x.

30. Brown A, Rance J, Warren L. Body image concerns are associated with a shorter breast feeding duration. Midwifery 2015;31(1):80-89. DOI: 10.1016/j.midw.2014.06.003.

31. Johnston-Robledo I, Fred V. Self-objectification and lower income pregnant women's breastfeeding attitudes. J Appl Soc Psychol 2008;38(1):1-21. DOI: 10.1111/j.1559-1816.2008.00293.x.

32. Clark A, Skouteris H, Wertheim EH, et al. My baby body: a qualitative insight into women's body-related experiences and mood during pregnancy and the postpartum. J Reprod Infant Psychol 2009,27(4):330-345. DOI: 10.1080/02646830903190904.

33. Devine CM, Bove CF, Olson CM. Continuity and change in women's weight orientations and lifestyle practices through pregnancy and the postpartum period: the influence of life course trajectories and transitional events. Soc Sci Med 2000;50(4):567-582. DOI: 10.1016/ s0277-9536(99)00314-7.

34. Bahadinbeigy K, Garrusi B, Etminam A, et al. Contributing factors affecting body satisfaction among pregnant women with an emphasis on self-esteem \& depression. Int J Caring Sci 2014 May;7(2):530-536.

35. Morin KH, Brogan S, Flavin SK. Attitudes and perceptions of body image in postpartum African American women. MCN Am J Matern Child Nurs 2002 Jan-Feb;27(1):20-25. DOI: 10.1097/00005721-200201000-00008. 